\title{
Evaluation of Strain Elastography for Differentiation of Thyroid Nodules: Results of a Prospective DEGUM Multicenter Study
}

\section{Evaluation der Strain Elastografie für die Differenzierung von Schilddrüsenknoten: Ergebnisse einer prospektiven DEGUM Multizenter-Studie}

Authors

Affiliations
M. Friedrich-Rust ${ }^{1^{*}}$, C. Vorlaender ${ }^{2^{*}}$, C. F. Dietrich ${ }^{3}$, W. Kratzer $^{4}$, W. Blank ${ }^{5}$, A. Schuler ${ }^{6}$, N. Broja ${ }^{1}$, X. W. Cui ${ }^{3,7}$, E. Herrmann ${ }^{8}$, J. Bojunga ${ }^{1}$

Affiliation addresses are listed at the end of the article.
Key words

- elastography

O thyroid

- strain elastography

received $\quad 30.10 .2015$ accepted 22.2.2016

Bibliography

DOI http://dx.doi.org/ 10.1055/s-0042-104647

Published online: April 12, 2016 Ultraschall in Med 2016; 37: 262-270 ๑ Georg Thieme Verlag KG Stuttgart · New York . ISSN 0172-4614

\section{Correspondence}

Prof. Dr. Mireen Friedrich-Rust Department of Internal

Medicine 1, J.W. Goethe-

University Hospital

Theodor-Stern-Kai 7

60590 Frankfurt

Germany

Tel.: ++ 49/69/630183735

Fax: ++49/69/63015122

Mireen.Friedrich-Rust@kgu.de

\section{Abstract}

$\nabla$

Purpose: Many patients with thyroid nodules are presently referred to surgery for not only therapeutic but also diagnostic purposes. The aim of noninvasive diagnostic methods is to optimize the selection of patients for surgery. Strain elastography (SE) enables the ultrasound-based determination of tissue elasticity. The aim of the present study was to evaluate the value of SE for the differentiation of thyroid nodules in a prospective multicenter study.

Materials and Methods: The study was registered at clinicaltrials.gov and was approved by the local ethics committees of all participating centers. All patients received an ultrasound (US) of the thyroid gland including color Doppler US. In addition, all nodules were evaluated by SE (Hitachi Medical Systems) using qualitative image interpretation of color distribution (SE-ES), strain value and strain ratio.

Results: Overall, 602 patients with 657 thyroid nodules (567 benign, 90 malignant) from 7 centers were included in the final analysis. The sensitivity, specificity, NPV, PPV, +LR were $21 \%, 73 \%$, $86 \%, 11 \%, 0.8$, respectively, for color Doppler US; $69 \%, 75 \%, 94 \%, 30 \%$, 2.9, respectively, for SE-ES; $56 \%, 81 \%, 92 \%, 32 \%, 2.9$, respectively, for SEstrain value; and $58 \%, 78 \%, 92 \%, 30 \%, 2.6$, respectively, for SE-strain ratio. The diagnostic accuracy was $71 \%$ for both strain value and strain ratio of nodules.

Conclusion: SE as an additional ultrasound tool improves the value of ultrasound for the workup of thyroid nodules. It might reduce diagnostic surgery of thyroid nodules in the future.

\section{Zusammenfassung \\ $\nabla$}

Ziel: Viele Patienten mit Schilddrüsenknoten werden nicht nur therapeutisch, sondern auch zu diagnostischem Zweck operiert. Ziel von nicht-invasiven diagnostischen Verfahren ist es daher die Selektion von Patienten zur Operation zu optimieren. Strain Elastografie (SE) ermöglicht die Ultraschall-basierte Messung der Gewebeelastizität. Das Ziel der vorliegenden Studie war es den Stellenwert der SE in einer prospektiven Multizenter-Studie für die Differenzierung von Schilddrüsenknoten zu evaluieren.

Material und Methoden: Die Studie wurde bei clinicaltrials.gov registriert und von den lokalen Ethikkommissionen der teilnehmenden Zentren genehmigt. Alle Patienten erhielten einen Ultraschall (US) der Schilddrüse inklusive FarbduplexUS. Zusätzlich wurden alle Knoten mittels SE (Hitachi Medical System) untersucht und eine Beurteilung der qualitativen Farbverteilung (SEES) und eine semiquantitative Messung der Elastizität mittels strain value und strain ratio durchgeführt.

Ergebnisse: Insgesamt wurden 602 Patienten mit 657 Schilddrüsenknoten (567 benigne, 90 maligne) an 7 deutschen Zentren ausgewertet. Sensitivität, Spezifität, NPV, PPV, und +LR betrugen entsprechend $21 \%, 73 \%, 86 \%, 11 \%, 0,8$ für den Duplex-US; 69\%, 75\%, 94\%, 30\%, 2,9 für SE-ES; $56 \%, 81 \%, 92 \%, 32 \%, 2,9$ für SE-strain value; $58 \%$, $78 \%, 92 \%, 30 \%, 2,6$ für SE- strain ratio. Die diagnostische Genauigkeit betrug $71 \%$ sowohl für SEstrain value, als auch SE-strain ratio.

Schlussfolgerung: Strain Elastografie als zusätzliche Ultraschallfunktion verbessert die Ultraschall-Diagnostik von Schilddrüsenknoten und könnte in Zukunft die Zahl der diagnostischen Operationen von Schilddrüsenknoten reduzieren. 


\section{Introduction}

\section{$\nabla$}

In regions with inadequate iodine supply such as in Germany, thyroid nodules are a common finding and are reported in one third of unselected adults [1]. For the detection of thyroid nodules, ultrasound (US) is an excellent method, but it only has low accuracy for differentiation between benign and malignant thyroid nodules [2]. Presently fine-needle aspiration biopsy (FNAB) is recommended as an additional diagnostic method in the evaluation of thyroid nodules with a size of $\geq 10 \mathrm{~mm}$ in patients with normal thyroid stimulating hormone. In addition, FNAB is also advised in nodules smaller than $10 \mathrm{~mm}$ with suspicious US findings or suspicious history [3 - 7]. However, besides high specificities (60 - 98\%), varying sensitivities (54-90\%) have been reported for FNAB for the diagnosis of malignant thyroid nodules [8-11]. Therefore, a relevant number of patients with the final diagnosis of benign thyroid nodules receive thyroid surgery. Surgery is therefore performed more for diagnostic than for therapeutic purposes [12].

A classic criterion of malignancy upon palpation or US probe pressure is a hard or firm consistency $[3,13]$. With the introduction of strain elastography (SE), a reproducible qualitative and semi-quantitative assessment of tissue consistency became available. Most US companies now offer elastography as an additional tool integrated in conventional high-end US machines [14, 15]. Meta-analyses of SE reported mean sensitivities of $82-92 \%$ and mean specificities of $67-92 \%$ for the diagnosis of malignant thyroid nodules [16 - 18]. However, SE was also challenged and criticized for its operator dependency in studies [19].

The aim of the present study was to evaluate strain elastography for the differentiation of thyroid nodules in a prospective multicenter study in patients referred for work-up of thyroid nodules.

\section{Materials and Methods}

The multicenter study was approved by the lead ethics committee at the University of Frankfurt with local approval from the ethics committees of the other study centers. The study was registered with Clinicaltrials.gov with the registration number NCT01 609946.

Between May 2012 and October 2014, consecutive patients who attended the participating hospitals for cytological or histological assessment of thyroid nodules were evaluated for inclusion in the study. The patients were recruited from seven centers in Germany. Written informed consent was obtained from all patients. Inclusion criteria were age 18 and older, the presence of a thyroid nodule $\geq 5 \mathrm{~mm}$, normal values of thyroid-stimulating hormone (TSH $\geq 0.35 \mu \mathrm{U} / \mathrm{ml}$ ), and FNAB of this nodule performed within the last 6 months or FNAB and/or surgery planned at the time of US examination and finally performed within the study period. Exclusion criteria were pregnancy and lactation, cystic lesions of completely liquid nature, no cytology by FNAB or histology by surgery of the thyroid nodule within the study period, indeterminate cytology by FNAB without repeated FNAB, and suspicious or malignant cytology by FNAB without thyroid operation within the study period.

All patients received a US scan of the thyroid gland including color Doppler US followed by SE (Hitachi Medical Systems) using qualitative image interpretation of color distribution (SE-ES), strain value and strain ratio in real-time.

An online case report form was used for data collection.

\section{Reference method - cytology/histology}

Cytology with a 6-12-month follow-up US scan (showing absence of lesion growth - increase in diameter of less than $20 \%$ or increase in volume of less than $50 \%$ ) or histology was used as the reference method for the diagnosis of benign thyroid nodules $[3,7]$.

FNAB was performed with a 25-gauge needle attached to a $20-\mathrm{ml}$ syringe. Adequacy of aspirates was defined according to the guidelines of the Papanicolaou Society [20]. The Bethesda system was used to report thyroid cytopathology [21]. Patients with suspicious or malignant cytology were referred to surgery and were only included in the study if surgery was performed within the study period. Cytology and histology were read by experienced local pathologists with at least 5 years of working experience who were blinded to the results of US and elastography. Histology was used as the reference method for the diagnosis of malignant thyroid nodules.

One to two investigators (all physicians) were involved in ultrasound scanning at each center. The same investigator performed all US and SE measurement in the same patient and interpreted the results. No change in examiners was done in between. The investigators at all centers had at least 10 years of experience in thyroid US and at least 6 months in elastography. The investigators were blinded to the results of cytology and histology.

\section{Conventional ultrasound (B-mode, Doppler)}

All patients received a US examination of the thyroid gland using a transducer at $9 \mathrm{MHz}$ (Hitachi HI Vision Preirus, HI Vision Avius, EUB 900 HV and EUB 7500 HV, Hitachi Medical Corporation, Japan). The patients were positioned in a supine position with dorsal flexion of the head. Thyroid nodules were evaluated for size, volume, echogenicity, echotexture, presence/absence of halo sign, presence/absence of microcalcification (hyperechoic spots $<1 \mathrm{~mm}$ ) and/or macrocalcification ( $>1 \mathrm{~mm}$ ). After B-mode US, power Doppler and duplex imaging were performed. Vascularization of thyroid nodules was classified using five different patterns as described previously [22]: pattern 0: no visible flow; pattern 1: minimal internal flow without a peripheral ring; pattern 2: peripheral ring of flow but minimal or no internal flow; pattern 3: peripheral ring of flow and moderate amount of internal flow; pattern 4: extensive internal flow with or without a peripheral ring.

In patients with a goiter and multiple nodules, up to 4 nodules per patient, which fulfilled at least 2 ultrasound criteria of malignancy, could be included. If more than 4 nodules fulfilled these criteria, hierarchically the nodules with the most ultrasound criteria of malignancy were selected. Each nodule was characterized independently.

\section{Strain Elastography (SE)}

Strain elastography was performed with a Hitachi Systems (Hitachi HI Vision Preirus, HI Vision Avius, EUB 900 HV and EUB 7500 HV, Hitachi Medical Corporation, Japan). The machines at the different centers were all standardized to the elastography parameters: frame rejection/noise rejection: 4-4, persistence: 6 , blending: 32, E.-Dyn: 4, density: 3, smoothing: 3, elastofreq.: low, frame rate: mid., color: fineflow: $500 \mathrm{~Hz}$; color Doppler: $800 \mathrm{~Hz}$, loops of 30 seconds. Tissue elasticity distribution is calculated by the strain and stress of the examined tissue. The calculation of tissue elasticity distribution was performed in real-time and the examination results were represented as color-coded images over the conventional B-mode image (blue=hard, red \& 
green $=$ soft tissue). Details have been described in previous studies $[23,24]$. The probe was placed on the neck and a light pressure of $3-4$ on a scale of $0-6$ arbitrary units was applied for measurement. The region-of-interest (ROI) for the elastography examination was selected by the operator including the nodule and surrounding normal thyroid tissue. Elasticity was classified in four different patterns as described previously [25 - 27]:

$\checkmark$ Elasticity score (ES)-1: the nodule is displayed homogeneously in green (soft)

ES-2: the nodule is displayed predominantly in green with few blue areas/spots

ES-3: the nodule is displayed predominantly in blue with few green areas/spots

ES-4: the nodule is displayed completely in blue (hard).

SE was recorded in a transverse and longitudinal position. SE was performed in real-time and images and/or clips were stored. Directly after storing of a representative SE image, the strain value calculation of the elasticity within an ROI was performed using the auto-correlations method (values of 1.0 indicate maximum elasticity) and the strain ratio (ratio of the strain value in the surrounding thyroid tissue and strain value in thyroid nodule) was calculated. The size of the ROI within the nodule was chosen to be as large as possible to include the nodule only, and the ROI in the healthy thyroid tissue was placed if possible at the same depth as the ROI in the nodule.

\section{Sample size calculation}

The primary study aim was the quantification of the sensitivity and specificity of SE for the diagnosis of malignant thyroid nodules with high diagnostic accuracy. As a primary statistical aim, confidence intervals of $95 \%$ were calculated for the sensitivity and specificity. Based on the results of a previous meta-analysis on SE [16], a sensitivity and specificity of at least $90 \%$ were assumed. To obtain intervals with a length of at most $5 \%$, a sample size of 593 patients was calculated.

\section{Statistical analysis}

Statistical analysis was performed using BiAS-for-Windows (version-10.03, epsilon-2013, Frankfurt, Germany). Clinical and laboratory characteristics of patients were expressed as mean $\pm S D$, median and range. The sensitivity, specificity, positive predictive values (PPV) and negative predictive values (NPV), and positive likelihood ratio (LR) were calculated for the diagnosis of malignant nodules for all ultrasound criteria and SE. Malignancy criteria were defined as follows for this purpose: hypoechogenicity, irregular margin, absent halo sign, pattern $3 \& 4$ vascularization, presence of microcalcification, elastography ES score $3 \& 4$. All tests were two-sided and use a significance level of $\alpha=5 \%$. The diagnostic performance of semi-quantitative SE was also assessed by receiver-operating-characteristic (ROC) curves. The ROC curve represents sensitivity versus 1 -specificity for all possible cut-off values for the prediction of malignancy. The statistical program R (R Foundation for Statistical Computing, Vienna, Austria), particularly the R package pROC [28] was used to obtain an optimal combination of ultrasound criteria with respect to the Youden criteria consisting of microcalcification, macrocalcification, hypoechogenicity, absent halo sign, irregular margins, pattern 3-4 vascularization, ES 3-4 transverse and longitudinal and strain value $<0.17$, strain ratio $>2.66$.

\section{Results}

$\nabla$

646 patients with 701 thyroid nodules were prospectively enrolled at 7 centers in this multicenter study. 36 patients were excluded due to missing data on SE results or cytology/histology. Additionally 8 patients with malignant cytology who did not receive surgery within the study period were excluded. Therefore, 602 patients with 657 thyroid nodules were available for final analysis. In 47 patients with a goiter, 2 nodules per patient were included and in 4 patients 3 nodules per patient were included. Patient characteristics are shown in $\bullet$ Table 1. Thyroid hormone values were within normal range in all patients.

FNAB was performed in 214 nodules of 198 patients. According to the Bethesda System for reporting thyroid cytopathology, these were: Bethesda category I in 3 nodules, Bethesda-II (benign) in 160 nodules, Bethesda-III in 19, Bethesda-IV in 27 and Bethesda$\mathrm{V}$ in 5 nodules. 145 of 160 nodules with Bethesda classification II (benign) without growth within 6 months were classified as benign lesions without histology. All patients with nodules with Bethesda-I and Bethesda-III-V, as well as 15 patients with nodules with Bethesda-II and a goiter received surgery within the study period. In addition, 443 nodules of patients presented to primary surgery.

Finally, 483 patients with 512 nodules were operated on. The final diagnosis of benign histology was papillary adenoma in 29 nodules, follicular adenoma in 79, microfollicular adenoma in 53 , oncocytic adenoma in 4, thyroid hyperplasia in 6 and goiter in 251 evaluated nodules. The final diagnosis of malignant histology was papillary carcinoma in 77 patients with 78 nodules, medullary carcinoma in 10 patients/nodules, follicular carcinoma in 1 patient/nodule, and anaplastic carcinoma in 1 patient/nodule. Therefore, in total 567 benign nodules from 515 patients and 90 malignant nodules from 87 patients were analyzed.

\section{Imaging}

Details on SE-scoring are shown in $\bullet$ Table 1. Results of B-mode US, duplex US and SE are shown in 0 Table 2. The diagnostic accuracy for the diagnosis of malignant nodules was $71 \%$ for strain value $(95 \%-\mathrm{CI}: 0.65 ; 0.77)$ and $71 \%$ for strain ratio $(0.64 ; 0.77)$. The optimal cut-off (highest sum of sensitivity and specificity) was 0.17 for strain value and 2.66 for strain ratio (strain value thyroid tissue/strain value nodule) for the diagnosis of malignant thyroid nodules. Details are shown in 0 Table 2. No significant difference in diagnostic accuracy was observed between strain value, strain ratio, and SE color classification. The diagnostic value of different combinations of US criteria as well as combinations of US with SE is shown in 0 Table 3, 4 and supplementary Table 1. Overall, 185 benign and 61 malignant nodules had irregular margins; 129 benign and 39 malignant nodules were round, 397 benign and 28 malignant nodules were oval, and 31 benign and 22 malignant nodules were polycyclic. Depending on the combination of US criteria, 12 - 51 malignant nodules misclassified by B-mode/Doppler ultrasound could be correctly diagnosed by elastography. To estimate the optimal combination of imaging criteria, sum scores 1 to optimize the Youden index were calculated including (1) B-mode criteria only, (2) B-mode and power Doppler US, and (3) B-mode, power Doppler and SE:

(1) For B-mode criteria the optimal sum score consisted of the two criteria: microcalcification and absent halo sign. This score results in a sensitivity of $54.5 \%$, specificity of $91.8 \%$, NPV of $92.7 \%$, PPV of $51.6 \%$, +LR of 6.7 , and -LR of 0.5 . 
Table 1 Patients characteristics.

\begin{tabular}{|c|c|c|c|c|}
\hline characteristics & $\begin{array}{l}\text { all } 602 \text { patients with } \\
657 \text { nodules }\end{array}$ & $\begin{array}{l}515 \text { patients with } 567 \\
\text { benign nodules }\end{array}$ & $\begin{array}{l}87 \text { patients with } 90 \\
\text { malignant nodules }\end{array}$ & p-value \\
\hline \multicolumn{5}{|l|}{ centers } \\
\hline University Hospital Frankfurt (\%) & $128(19.5)$ & $114(20.1)$ & $14(15.6)$ & \\
\hline Caritas Hospital Bad Mergentheim (\%) & $138(21.0)$ & $129(22.8)$ & $9(10.0)$ & \\
\hline Buergerhospital Frankfurt (\%) & $234(35.6)$ & $180(31.7)$ & $54(60.0)$ & \\
\hline University Hospital UIm (\%) & $54(8.2)$ & $48(8.5)$ & $6(6.7)$ & \\
\hline Hospital Reutlingen (\%) & $52(7.9)$ & $51(9.0)$ & $1(1.1)$ & \\
\hline Helfenstein Hospital Geislingen (\%) & $48(7.3)$ & $42(7.4)$ & $6(6.7)$ & \\
\hline Sana Hospital Luebeck (\%) & $3(0.5)$ & $3(0.5)$ & $0(0)$ & \\
\hline patient age (years) & & & & $<0.001$ \\
\hline mean $\pm S D$ & $52.4 \pm 13.6$ & $53.5 \pm 13.1$ & $45.6 \pm 14.2$ & \\
\hline range & $18-90$ & $18-90$ & $21-78$ & \\
\hline median & 52 & 53 & 44 & \\
\hline male gender, $\mathrm{n}(\%)$ & $209(31.8)$ & $185(32.6)$ & $24(26.7)$ & $>0.20$ \\
\hline single nodule, $n(\%)$ & $217(33.0)$ & $177(31.2)$ & $40(44.4)$ & 0.018 \\
\hline goiter, n (\%) & $377(57.4)$ & $332(58.6)$ & $45(50.0)$ & \\
\hline nodule location & & & & $>0.20$ \\
\hline left, n (\%) & $326(50.2)$ & $282(50.4)$ & $44(48.9)$ & \\
\hline right, n (\%) & $292(44.9)$ & $249(44.5)$ & $41(45.6)$ & \\
\hline isthmus, $\mathrm{n}(\%)$ & $32(4.9)$ & $29(5.2)$ & $3(3.3)$ & \\
\hline nodule size & & & & $<0.001$ \\
\hline mean $\pm S D$ & $7.4 \pm 11.5$ & $7.7 \pm 12.1$ & $3.6 \pm 5.9$ & \\
\hline range & $0.015-101.2$ & $0.015-101.2$ & $0.03-28.6$ & \\
\hline median & 3.24 & 3.6 & 2.38 & \\
\hline scintigraphy of nodule ${ }^{1}$ & & & & 0.02 \\
\hline hypofunctioning, n (\%) & $421(88.8)$ & $359(88.0)$ & $62(93.9)$ & \\
\hline indifferent, n (\%) & $51(10.8)$ & $48(11.8)$ & $3(4.5)$ & \\
\hline cytology of nodule, n (\%) & $214(32.6)$ & $183(32.3)$ & $31(34.4)$ & $<0.001$ \\
\hline histology of nodule, n (\%) & $512(77.9)$ & $422(74.4)$ & $90(100)$ & $<0.001$ \\
\hline real-time elastography score & & & & $<0.001$ \\
\hline \multicolumn{5}{|l|}{ transverse } \\
\hline ES 1, n (\%) & $79(12.0)$ & $77(13.7)$ & $2(2.2)$ & \\
\hline ES 2, n (\%) & $373(57.1)$ & 347 (61.5) & $26(29.2)$ & \\
\hline ES 3, n (\%) & $172(26.3)$ & $125(22.2)$ & $47(52.8)$ & \\
\hline ES 4, n (\%) & $29(4.4)$ & $15(2.7)$ & $14(15.7)$ & \\
\hline real-time elastography score & & & & $<0.001$ \\
\hline \multicolumn{5}{|l|}{ longitudinal } \\
\hline ES 1, n (\%) & $77(11.8)$ & $75(13.3)$ & $2(2.2)$ & \\
\hline ES 2, n (\%) & $355(54.4)$ & $330(58.7)$ & $25(27.8)$ & \\
\hline ES 3, n (\%) & $183(28.1)$ & $138(24.6)$ & $45(50.0)$ & \\
\hline ES 4, n (\%) & $37(5.7)$ & $19(3.4)$ & $18(20.0)$ & \\
\hline
\end{tabular}

$\mathrm{SD}=$ standard deviation

${ }^{1}$ Scintigraphy of nodule available in 429 patients with 474 nodules.

(2) Including power Doppler US did not change the optimal sum score. Power Doppler was not selected itself.

(3) For the combination of US criteria and SE, the optimal sum score consisted of: microcalcifications, macrocalcification, absent halo sign, irregular margins, pattern 3 - 4 vascularization, ES 3 - 4 longitudinal, strain ratio $>2.66$. Each fulfilled criterion adds one point to the sum score. If 4 or more of these criteria indicate malignancy, the score results in a sensitivity of $68.2 \%$, specificity of $85.1 \%$, NPV of $94.1 \%$, PPV of $43.6 \%$, +LR of 4.6 and $-\mathrm{LR}$ of 0.4 . (० Fig. 1, 2)

\section{Discussion}

Strain elastography is a qualitative elastography method evaluating changes in US pattern during strain and stress of direct or indirect tissue compression. Meta-analyses of SE reported mean sensitivities of $82-92 \%$ and specificities of $67-92 \%$ for the diagnosis of malignant thyroid nodules [14-18]. Variable scoring categories of SE have been evaluated: qualitative assessment using a 4-scale scoring system (as used in the present study), a 5-scale scoring system and semi-quantitative scoring using strain value, strain ratio, histograms of color pixels and ECI index [14, 15, 2934]. Nevertheless, besides a lot of promising study results, studies have also challenged the usefulness of SE in clinical practice by reporting no additional value as compared to qualified B-mode US [19, 35, 36].

The aim of the present study was to evaluate high-quality conventional US performed by physicians with significant experience in ultrasound as well as SE using a qualitative 4-scale scoring system as well as the semi-quantitative strain value and strain ratio in a prospective multicenter study in patients referred for work-up of thyroid nodules. Overall, 602 patients with 657 thyroid nodules were analyzed and the negative predictive 
Table 2 Diagnostic value of US and SE for the diagnosis of malignant thyroid nodules.

\begin{tabular}{|c|c|c|c|c|c|c|c|c|}
\hline criteria & benign & $\begin{array}{l}\text { malig- } \\
\text { nant }\end{array}$ & sens (\%) & spec (\%) & NPV (\%) & PPV (\%) & $+\mathrm{LR}$ & $-\mathrm{LR}$ \\
\hline \multicolumn{9}{|c|}{ hypoechogenicity } \\
\hline yes & 288 & 64 & 71.1 & 47.7 & 91.0 & 18.2 & 1.4 & 0.6 \\
\hline no & 263 & 26 & $(60.6 ; 80.2)$ & $(43.5 ; 52.0)$ & $(87.1 ; 94.0)$ & $(14.3 ; 22.6)$ & $(1.2 ; 1.6)$ & $(0.4 ; 0.8)$ \\
\hline \multicolumn{9}{|c|}{ microcalcifications } \\
\hline yes & 116 & 57 & 63.3 & 79.4 & 93.1 & 33.0 & 3.1 & 0.5 \\
\hline no & 447 & 33 & $(52.5 ; 73.3)$ & $(75.8 ; 82.7)$ & $(90.5 ; 95.2)$ & $(26.0 ; 40.5)$ & $(2.5 ; 3.9)$ & $(0.4 ; 0.6)$ \\
\hline \multicolumn{9}{|c|}{ macrocalcifications } \\
\hline yes & 118 & 15 & 16.9 & 78.9 & 85.7 & 11.3 & 0.8 & 1.1 \\
\hline no & 442 & 74 & $(9.8 ; 26.3)$ & $(75.3 ; 82.2)$ & $(82.3 ; 88.6)$ & $(6.5 ; 17.9)$ & $(0.5 ; 1.3)$ & $(1.0 ; 1.2)$ \\
\hline \multicolumn{9}{|c|}{ absent halo sign } \\
\hline yes & 183 & 61 & 69.3 & 66.9 & 93.2 & 25.0 & 2.1 & 0.5 \\
\hline no & 370 & 27 & $(58.6 ; 78.7)$ & $(62.8 ; 70.8)$ & $(90.3 ; 95.5)$ & $(19.7 ; 30.9)$ & $(1.7 ; 2.5)$ & $(0.3 ; 0.6)$ \\
\hline \multicolumn{9}{|c|}{ irregular margins } \\
\hline yes & 185 & 61 & 67.8 & 66.7 & 92.7 & 24.8 & 2.0 & 0.5 \\
\hline no & 369 & 29 & $(57.1 ; 77.3)$ & $(62.6 ; 70.6)$ & $(89.7 ; 95.1)$ & $(19.5 ; 30.7)$ & $(1.7 ; 2.4)$ & $(0.4 ; 0.7)$ \\
\hline \multicolumn{9}{|c|}{ oval shape } \\
\hline yes & 397 & 28 & 31.5 & 28.7 & 72.4 & 6.6 & 0.4 & 2.4 \\
\hline no & 160 & 61 & $(22.0 ; 42.2)$ & $(25.0 ; 32.7)$ & $(66.0 ; 78.2)$ & $(4.4 ; 9.4)$ & $(0.3 ; 0.6)$ & $(2.0 ; 2.9)$ \\
\hline \multicolumn{9}{|c|}{$\begin{array}{l}\text { pattern } 3-4 \\
\text { vascularization }\end{array}$} \\
\hline yes & 150 & 19 & 21.4 & 73.4 & 85.5 & 11.2 & 0.8 & 1.1 \\
\hline no & 413 & 70 & $(13.4 ; 31.3)$ & $(69.5 ; 77.0)$ & $(82.1 ; 88.5)$ & $(6.9 ; 17.0)$ & $(0.5 ; 1.2)$ & $(1.0 ; 1.2)$ \\
\hline \multicolumn{9}{|c|}{ ES 3- 4 transverse } \\
\hline yes & 140 & 61 & 68.5 & 75.2 & 93.8 & 30.4 & 2.8 & 0.4 \\
\hline no & 424 & 28 & $(57.8 ; 78.0)$ & $(71.4 ; 78.7)$ & $(91.2 ; 95.8)$ & $(24.1 ; 37.2)$ & $(2.3 ; 3.4)$ & $(0.3 ; 0.6)$ \\
\hline \multicolumn{9}{|l|}{ ES 3-4 } \\
\hline \multicolumn{9}{|c|}{ longitudinal } \\
\hline yes & 157 & 63 & 70.0 & 72.1 & 93.8 & 28.6 & 2.5 & 0.4 \\
\hline no & 405 & 27 & $(59.4 ; 79.2)$ & $(68.2 ; 75.7)$ & $(91.0 ; 95.8)$ & $(22.8 ; 35.1)$ & $(2.1 ; 3.0)$ & $(0.3 ; 0.6)$ \\
\hline \multicolumn{9}{|c|}{$\begin{array}{l}\text { strain value } \\
\text { nodule }<0.17\end{array}$} \\
\hline yes & 108 & 50 & 56.2 & 80.6 & 92.0 & 31.7 & 2.9 & 0.5 \\
\hline no & 448 & 39 & $(45.3 ; 66.7)$ & $(77.0 ; 83.8)$ & $(89.2 ; 47.6)$ & $(24.4 ; 39.5)$ & $(2.3 ; 3.7)$ & $(0.4 ; 0.7)$ \\
\hline \multicolumn{9}{|c|}{ strain ratio > 2.66} \\
\hline yes & 121 & 52 & 58.4 & 77.7 & 92.0 & 30.1 & 2.6 & 0.5 \\
\hline no & 422 & 37 & $(47.5 ; 68.8)$ & $(74.0 ; 81.2)$ & $(89.1 ; 94.3)$ & $(23.3 ; 37.5)$ & $(2.1 ; 3.3)$ & $(0.4 ; 0.7)$ \\
\hline
\end{tabular}

Not all criteria were recorded for each nodule. Therefore, the numbers in each column do not always total 567 benign and 90 malignant nodules.

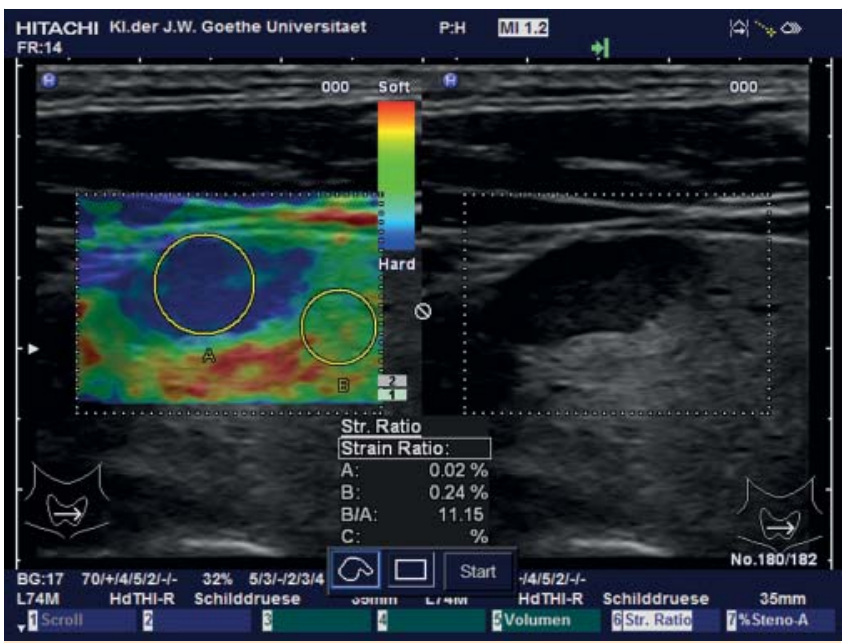

Fig. 1 Example of SE of papillary carcinoma: An $8 \times 12 \mathrm{~mm}$ nodule in the right thyroid gland classified as SE ES-4 (completely blue = hard; consistent with malignancy) with strain ratio of 11.15 . Histology revealed a papillary T2 carcinoma.

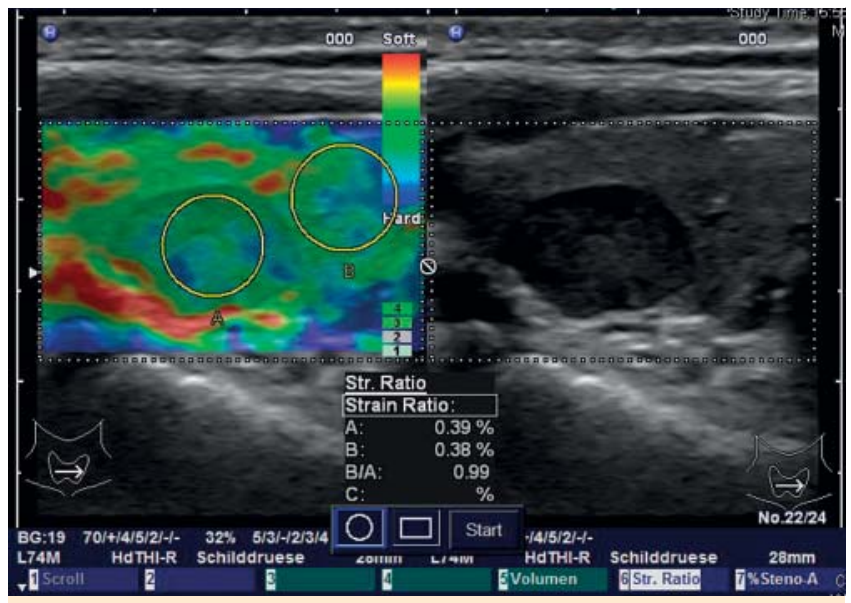

Fig. 2 Example of SE of thyroid adenoma: An $8 \times 12 \mathrm{~mm}$ nodule in the right thyroid gland classified as SE 2 (predominantly green = soft; consistent with benign nodule) with strain ratio of 0.99 . Histology revealed a benign papillary thyroid adenoma. 
Table 3 Diagnostic value of US combinations for the diagnosis of malignant thyroid nodules (dual combination).

\begin{tabular}{|c|c|c|c|c|c|c|c|c|}
\hline US pattern & benign & malignant & $\begin{array}{l}\text { sensitivity } \\
\text { (\%) }\end{array}$ & $\begin{array}{l}\text { specificity } \\
\text { (\%) }\end{array}$ & NPV (\%) & PPV (\%) & $+\mathrm{LR}$ & $-\mathbf{L R}$ \\
\hline \multicolumn{9}{|c|}{$\begin{array}{l}\text { hypoechogenicity + } \\
\text { absent halo sign }\end{array}$} \\
\hline yes & 113 & 50 & 56.8 & 79.0 & 91.8 & 30.7 & 2.7 & 0.5 \\
\hline no & 425 & 38 & $(45.8 ; 67.3)$ & $(75.3 ; 82.4)$ & $(88.9 ; 94.1)$ & $(23.7 ; 38.4)$ & $(2.1 ; 3.5)$ & $(0.4 ; 0.7)$ \\
\hline \multicolumn{9}{|c|}{$\begin{array}{l}\text { hypoechogenicity + } \\
\text { microcalcification }\end{array}$} \\
\hline yes & 64 & 47 & 52.2 & 88.3 & 91.9 & 42.3 & 4.5 & 0.5 \\
\hline no & 485 & 43 & $(41.4 ; 63.9)$ & $(85.4 ; 90.9)$ & $(89.2 ; 94.0)$ & $(33.0 ; 52.1)$ & $(3.3 ; 6.1)$ & $(0.4 ; 0.7)$ \\
\hline \multicolumn{9}{|c|}{$\begin{array}{l}\text { microcalcification + } \\
\text { absent halo sign }\end{array}$} \\
\hline yes & 45 & 48 & 54.6 & 91.8 & 92.7 & 51.6 & 6.7 & 0.5 \\
\hline no & 504 & 40 & $(43.6 ; 65.2)$ & $(89.2 ; 94.0)$ & $(90.1 ; 94.7)$ & $(41.0 ; 62.1)$ & $(4.7 ; 9.3)$ & $(0.4 ; 0.6)$ \\
\hline \multicolumn{9}{|c|}{$\begin{array}{l}\text { pattern } 4 \text { vasc. }{ }^{+} \\
\text {hypoechogenicity }\end{array}$} \\
\hline yes & 26 & 5 & 5.6 & 95.3 & 86.1 & 16.1 & 1.2 & 1.0 \\
\hline no & 521 & 84 & $(1.9 ; 12.6)$ & (93.1;96.9) & $(83.1 ; 88.8)$ & $(5.5 ; 33.7)$ & $(0.5 ; 3.0)$ & $(0.9 ; 1.0)$ \\
\hline \multicolumn{9}{|c|}{$\begin{array}{l}\text { pattern } 4 \text { vasc. }{ }^{+} \\
\text {microcalcification }\end{array}$} \\
\hline yes & 11 & 4 & 4.5 & 98.0 & 86.6 & 26.7 & 2.3 & 1.0 \\
\hline no & 548 & 85 & $(1.2 ; 11.1)$ & $(96.5 ; 99.0)$ & $(83.7 ; 89.1)$ & $(7.8 ; 55.1)$ & $(0.7 ; 7.0)$ & $(0.9 ; 1.0)$ \\
\hline \multicolumn{9}{|c|}{$\begin{array}{l}\text { pattern } 4 \text { vasc. + } \\
\text { absent halo sign }\end{array}$} \\
\hline yes & 12 & 3 & 3.5 & 97.8 & 86.5 & 20.0 & 1.6 & 1.0 \\
\hline no & 537 & 84 & $(0.7 ; 9.8)$ & (96.2;98.9) & $(83.5 ; 89.1)$ & $(4.3 ; 48.1)$ & $(0.5 ; 5.5)$ & $(0.9 ; 1.0)$ \\
\hline \multicolumn{9}{|c|}{$\begin{array}{l}\text { irregular margins + } \\
\text { hypoechogenicity }\end{array}$} \\
\hline yes & 105 & 47 & 52.2 & 80.6 & 91.0 & 30.9 & 2.7 & 0.6 \\
\hline no & 436 & 43 & $(41.4 ; 62.9)$ & $(77.0 ; 83.8)$ & $(88.1 ; 93.4)$ & $(23.7 ; 38.9)$ & $(2.1 ; 3.5)$ & $(0.5 ; 0.7)$ \\
\hline \multicolumn{9}{|c|}{$\begin{array}{l}\text { irregular margins + } \\
\text { microcalcification }\end{array}$} \\
\hline yes & 50 & 48 & 54.6 & 90.9 & 92.6 & 49.0 & 6.0 & 0.5 \\
\hline no & 500 & 42 & $(43.6 ; 65.2)$ & $(88.2 ; 93.2)$ & $(90.1 ; 94.7)$ & $(38.7 ; 59.3)$ & $(4.3 ; 8.3)$ & $(0.4 ; 0.6)$ \\
\hline \multicolumn{9}{|c|}{$\begin{array}{l}\text { irregular margins + } \\
\text { absent halo sign }\end{array}$} \\
\hline yes & 105 & 52 & 59.1 & 80.7 & 92.4 & 33.1 & 3.1 & 0.5 \\
\hline no & 438 & 36 & $(48.1 ; 69.5)$ & $(77.1 ; 83.9)$ & $(89.6 ; 94.6)$ & $(25.8 ; 41.1)$ & $(2.4 ; 3.9)$ & $(0.4 ; 0.7)$ \\
\hline \multicolumn{9}{|c|}{$\begin{array}{l}\text { irregular margins + } \\
\text { pattern } 4 \text { vasc. }\end{array}$} \\
\hline yes & 14 & 4 & 4.5 & 97.5 & 86.3 & 22.2 & 1.8 & 1.0 \\
\hline no & 536 & 85 & $(1.2 ; 11.1)$ & $(95.8 ; 98.6)$ & $(83.4 ; 88.9)$ & $(6.4 ; 47.6)$ & $(0.6 ; 5.2)$ & $(0.9 ; 1.0)$ \\
\hline
\end{tabular}

Not all criteria were recorded for each nodule. Therefore, the numbers in each column do not always total 567 benign and 90 malignant nodules.

value (NPV) of the different SE methods was $>90 \%$. These results are in accordance with previously published studies reporting NPV of $88-99 \%[25,27,33,37-43]$. Meta-analyses of SE reported mean sensitivities of $82-92 \%$ and mean specificities of 67 $92 \%$ for the diagnosis of malignant thyroid nodules [16-18]. In the present study the sensitivity of SE was $69-70 \%$ and the specificity was $72-75 \%$. SE was recorded in a transverse and longitudinal position in the present study to evaluate any influence of positioning. The results support taking the best access since no significant difference was observed.

While in a recent meta-analysis [18] the semi quantitative analysis had a slightly higher sensitivity than the qualitative analysis, no significant difference was observed in the present study. Only performing qualitative analysis is time-saving and can be recommended if the examination is performed by examiners with substantial ultrasound experience like in the present study. However, semi-quantification with strain value and strain ratio might be helpful for more novice examiners. This assumption has to be evaluated in future studies. The optimal strain ratio cut-off was 2.66. This is in accordance with previously published strain ratios calculating the strain value of the thyroid gland divided by the strain value of the thyroid nodule ranging from $1.5-4.2$ [18]. In the present study only SE from the company Hitachi was used. However, other strain elastography methods have been evaluated with excellent diagnostic accuracy and interobserver agreement [44]. However, the strain elastography methods of different companies might not be directly comparable and might influence the calculation of strain value and strain ratio. Recently shear-wave elastography methods have been evaluated for the diagnosis of thyroid nodules. The results are comparable to the results of SE [45].

The combination of B-mode US criteria and SE could improve the noninvasive diagnosis of malignant thyroid nodules in the present study. A sum score including B-mode and SE increased sensitivity by $14 \%$ and NPV by $2 \%$ as compared to B-mode/Doppler US alone. Depending on the combination of US criteria, 12 - 51 ma- 
Table 4 Diagnostic value of US in combination with SE for the diagnosis of malignant thyroid nodules (dual combination).

\begin{tabular}{|c|c|c|c|c|c|c|c|c|}
\hline US pattern & benign & malignant & $\begin{array}{l}\text { sensitivity } \\
\text { (\%) }\end{array}$ & $\begin{array}{l}\text { specificity } \\
\text { (\%) }\end{array}$ & NPV (\%) & PPV (\%) & $+\mathrm{LR}$ & $-\mathrm{LR}$ \\
\hline \multicolumn{9}{|c|}{$\begin{array}{l}\text { irregular margins + } \\
\text { ES 3- } 4 \text { transverse }\end{array}$} \\
\hline Yes & 60 & 49 & 55.1 & 89.1 & 92.5 & 45.0 & 5.1 & 0.5 \\
\hline No & 491 & 40 & $(44.1 ; 65.6)$ & $(86.2 ; 91.6)$ & $(89.9 ; 94.6)$ & $(35.4 ; 54.8)$ & $(3.7 ; 6.9)$ & $(0.4 ; 0.6)$ \\
\hline \multicolumn{9}{|c|}{$\begin{array}{l}\text { irregular margins + } \\
\text { ES 3-4 longitudinal }\end{array}$} \\
\hline yes & 68 & 51 & 56.7 & 87.6 & 92.5 & 42.9 & 4.6 & 0.5 \\
\hline no & 481 & 39 & $(45.8 ; 67.1)$ & $(84.6 ; 90.3)$ & $(89.9 ; 94.6)$ & $(33.8 ; 52.3)$ & $(3.4 ; 6.1)$ & $(0.4 ; 0.6)$ \\
\hline \multicolumn{9}{|c|}{$\begin{array}{l}\text { hypoechogenicity + } \\
\text { ES 3-4 transverse }\end{array}$} \\
\hline yes & 75 & 48 & 53.9 & 86.3 & 92.0 & 39.0 & 3.9 & 0.5 \\
\hline no & 473 & 41 & $(43.0 ; 64.6)$ & $(83.2 ; 89.1)$ & $(89.3 ; 94.2)$ & $(30.4 ; 48.2)$ & $(3.0 ; 5.2)$ & $(0.4 ; 0.7)$ \\
\hline \multicolumn{9}{|c|}{$\begin{array}{l}\text { hypoechogenicity + } \\
\text { ES 3-4 longitudinal }\end{array}$} \\
\hline yes & 81 & 49 & 54.4 & 85.7 & 92.2 & 37.7 & 3.8 & 0.5 \\
\hline no & 465 & 41 & $(43.6 ; 65.0)$ & $(82.6 ; 88.5)$ & $(89.6 ; 94.4)$ & $(29.4 ; 46.6)$ & $(2.9 ; 5.0)$ & $(0.4 ; 0.7)$ \\
\hline \multicolumn{9}{|c|}{$\begin{array}{l}\text { microcalcification + } \\
\text { ES 3-4 transverse }\end{array}$} \\
\hline yes & 53 & 47 & 52.8 & 90.5 & 92.4 & 47.0 & 5.6 & 0.5 \\
\hline no & 507 & 42 & $(41.9 ; 63.5)$ & $(87.8 ; 92.8)$ & $(89.8 ; 94.4)$ & $(36.9 ; 57.2)$ & $(4.0 ; 7.7)$ & $(0.4 ; 0.7)$ \\
\hline \multicolumn{9}{|c|}{$\begin{array}{l}\text { microcalcification + } \\
\text { ES 3-4 longitudinal }\end{array}$} \\
\hline yes & 57 & 49 & 54.4 & 89.8 & 92.5 & 46.2 & 5.3 & 0.5 \\
\hline no & 502 & 41 & $(43.6 ; 65.0)$ & $(87.0 ; 92.2)$ & $(89.9 ; 94.5)$ & $(36.5 ; 56.2)$ & $(3.9 ; 7.3)$ & $(0.4 ; 0.6)$ \\
\hline \multicolumn{9}{|c|}{$\begin{array}{l}\text { absent halo sign + } \\
\text { ES 3-4 transverse }\end{array}$} \\
\hline yes & 63 & 46 & 52.9 & 88.6 & 92.2 & 42.2 & 4.6 & 0.5 \\
\hline no & 487 & 41 & $(41.9 ; 63.7)$ & $(85.6 ; 91.1)$ & $(89.6 ; 94.4)$ & $(32.8 ; 52.0)$ & $(3.4 ; 6.3)$ & $(0.4 ; 0.7)$ \\
\hline \multicolumn{9}{|c|}{$\begin{array}{l}\text { absent halo sign }+ \\
\text { ES 3-4 longitudinal }\end{array}$} \\
\hline yes & 69 & 47 & 53.1 & 87.4 & 92.1 & 40.5 & 4.3 & 0.5 \\
\hline no & 480 & 41 & $(42.5 ; 64.1)$ & $(84.4 ; 90.1)$ & $(89.5 ; 94.3)$ & $(31.5 ; 50.0)$ & $(3.2 ; 5.7)$ & $(0.4 ; 0.7)$ \\
\hline \multicolumn{9}{|c|}{$\begin{array}{l}\text { ES } 3-4 \text { transverse + } \\
\text { pattern } 3-4 \text { vasc. }\end{array}$} \\
\hline yes & 42 & 12 & 13.6 & 92.5 & 87.2 & 22.2 & 1.8 & 0.9 \\
\hline no & 518 & 76 & $(7.3 ; 22.6)$ & $(90.0 ; 94.5)$ & $(84.3 ; 89.8)$ & $(12.0 ; 35.6)$ & $(1.0 ; 3.3)$ & $(0.9 ; 1.0)$ \\
\hline \multicolumn{9}{|c|}{$\begin{array}{l}\text { ES } 3-4 \text { longitudinal + } \\
\text { pattern } 3-4 \text { vasc. }\end{array}$} \\
\hline yes & 51 & 13 & 14.6 & 90.9 & 87.0 & 20.3 & 1.6 & 0.9 \\
\hline no & 507 & 76 & $(8.0 ; 23.7)$ & $(88.2 ; 93.1)$ & $(84.0 ; 89.6)$ & $(11.3 ; 32.2)$ & $(0.9 ; 2.8)$ & $(0.9 ; 1.0)$ \\
\hline
\end{tabular}

Not all criteria were recorded for each nodule. Therefore, the numbers in each column do not always total 567 benign and 90 malignant nodules.

lignant nodules misclassified by B-mode/Doppler ultrasound could be correctly diagnosed by elastography. This additive value has also been reported in previously published studies [43]. Therefore, SE should be used in addition to conventional US in the diagnostic work-up of thyroid nodules. For example, in patients with suspicious signs on conventional ultrasound but soft elastography values (ES1 - 2), FNAB should be performed. If cytology reveals a benign non-follicular lesion, follow-up can be recommended.

A limitation of the present study is the high percentage (14\%) of carcinoma. However, this is a general limitation of most studies performed at endocrinology and US centers with an average of even $30 \%$ of malignant thyroid nodules [16]. Cytology without lesion growth was accepted as the reference method for benign lesions as suggested by international guidelines [3, 7]. However, it might not be the perfect reference. Yet, only including histology would have a relevant bias and further increase the number of malignant lesions. And the aim of the study was to evaluate thy- roid nodules referred for further diagnostic work-up according to present guidelines. In addition, only one case of follicular carcinoma was included in the present study. Therefore, no statement on the diagnostic accuracy of SE for follicular carcinoma can be made. Previous studies have reported that both FNA and SE have difficulties in the diagnosis of follicular carcinoma $[3,16,27,38$, 46]. In a meta-analysis on SE including 8 studies, $44 \%$ of follicular carcinoma were not detected as malignant thyroid nodules using SE. Gross anatomy and cellular patterns of follicular carcinoma overlap with those of benign follicular adenoma and might be an explanation $[16,46]$. Nodules $<5 \mathrm{~mm}$ were excluded from the present study, so no statement can be made regarding this lesion size. Another limitation is that no minimum case number per center was proposed in the study design. However, the examination was performed in high volume centers with experienced examiners. For the calculation of strain value and ratio, the ROI size was adapted to the size of the nodule to obtain an overall elasticity value of the nodule. However, the size of the ROI might influ- 
ence the elasticity results. The inter-observer variability was not assessed in the present manuscript since each patient was only examined by one examiner.

In summary, strain elastography as an additional US tool improves the diagnostic value of US for the exclusion of malignant thyroid nodules. Qualitative and semi-quantitative elastography scores are comparably good.

\section{Supplement Tables see online.}

\section{Affiliations \\ 1 Department of Internal Medicine 1, J.W. Goethe-University Hospital, Frankfurt, Germany \\ 2 Department of General Surgery, Buergerhospital Frankfurt, Germany 3 Innere Medizin 2, Caritas Hospital, Bad Mergentheim, Germany \\ 4 Department of Internal Medicine I, University Hospital Ulm, Germany \\ 5 Medizinische Klinik 1, Hospital am Steinenberg, Reutlingen, Germany \\ 6 Department of Internal Medicine, Helfenstein Hospital, Geislingen, Germany \\ 7 Sino-German Research Center of Ultrasound in Medicine, The First Affiliated Hospital of Zhengzhou University, Zhengzhou, China \\ 8 Institute of Biostatistics and Mathematical Modelling, Faculty of Medicine, J.W. Goethe-University, Frankfurt, Germany}

\section{Acknowledgments}

We are grateful to Hitachi Medical Systems for providing some centres with a Hitachi US system and for providing identical SE parameters at all centres. In addition, we would like to thank Dr. Eike Burmester from Sana Clinic Luebeck for enrolling his patients.

\section{References}

1 Reiners C, Wegscheider K, Schicha $H$ et al. Prevalence of thyroid disorders in the working population of Germany: ultrasonography screening in 96278 unselected employees. Thyroid [Internet] 2004; 14: 926 932

2 Iannuccilli JD, Cronan JJ, Monchik JM. Risk for malignancy of thyroid nodules as assessed by sonographic criteria: the need for biopsy. J Ultrasound Med 2004; 23: 1455-1464

3 Cooper DS, Doherty GM, Haugen BR et al. Management guidelines for patients with thyroid nodules and differentiated thyroid cancer. Thyroid 2006; 16: 109-142

4 Dietlein $M$, Schicha $H$. Lifetime follow-up care is necessary for all patients with treated thyroid nodules. Eur J Endocrinol 2003; 148: $377-379$

5 Gharib H, Papini E, Paschke R et al. American Association of Clinical Endocrinologists, Associazione Medici Endocrinologi, and EuropeanThyroid Association Medical Guidelines for Clinical Practice for the Diagnosis and Management of Thyroid Nodules. Endocr Pract 2010; 16 (Suppl 1): $1-43$

6 Hegedus L. Clinical practice. The thyroid nodule. N Engl J Med 2004; 351: $1764-1771$

7 Haugen BR, Alexander EK, Bible KC et al. 2015 American Thyroid Association Management Guidelines for Adult Patients with Thyroid Nodules and Differentiated Thyroid Cancer. Thyroid [Internet] 2015, Available from: 20: http://www.ncbi.nlm.nih.gov/pubmed/26462967

8 La Rosa GL, Belfiore A, Giuffrida D et al. Evaluation of the fine needle aspiration biopsy in the preoperative selection of cold thyroid nodules. Cancer 1991; 67: 2137-2141

9 Oertel YC, Miyahara-Felipe L, Mendoza MG et al. Value of repeated fine needle aspirations of the thyroid: an analysis of over ten thousand FNAs. Thyroid 2007; 17: 1061 - 1066

10 Peng $Y$, Wang $H H$. A meta-analysis of comparing fine-needle aspiration and frozen section for evaluating thyroid nodules. Diagn Cytopathol 2008; 36: 916-920

11 Tee YY, Lowe AJ, Brand CA et al. Fine-needle aspiration may miss a third of all malignancy in palpable thyroid nodules: a comprehensive literature review. Ann Surg 2007; 246: 714-720
12 Wienhold R, Scholz M, Adler JB et al. The management of thyroid nodules-a retrospective analysis of health insurance data. Dtsch Arztebl Int 2013; 110: 827-834

13 Pacini F, Schlumberger M, Dralle $H$ et al. European consensus for the management of patients with differentiated thyroid carcinoma of the follicular epithelium. Eur J Endocrinol 2006; 154: 787-803

14 Bamber J, Cosgrove D, Dietrich CF et al. EFSUMB guidelines and recommendations on the clinical use of ultrasound elastography. Part 1 : Basic principles and technology. Ultraschall in Med 2013; 34: 169-184

15 Cosgrove D, Piscaglia F, Bamber J et al. EFSUMB guidelines and recommendations on the clinical use of ultrasound elastography. Part 2: Clinical applications. Ultraschall in Med 2013; 34: 238 - 253

16 Bojunga J, Herrmann E, Meyer $G$ et al. Realtime elastography for the differentiation of benign and malignant thyroid nodules: a meta-analysis. Thyroid 2010; 20: 1145 - 1150

17 Ghajarzadeh M, Sodagari F, Shakiba M. Diagnostic accuracy of sonoelastography in detecting malignant thyroid nodules: a systematic review and meta-analysis. Am J Roentgenol 2014; 202: W379-W389

18 Razavi SA, Hadduck TA, Sadigh G et al. Comparative effectiveness of elastographic and B-mode ultrasound criteria for diagnostic discrimination of thyroid nodules: a meta-analysis. Am J Roentgenol 2013; 200: $1317-1326$

19 Moon HJ, Sung JM, Kim EK et al. Diagnostic performance of gray-scale US and elastography in solid thyroid nodules. Radiology 2012; 262: $1002-1013$

20 Guidelines of the Papanicolaou Society of Cytopathology for the Examination of Fine-Needle Aspiration Specimens from Thyroid Nodules. The Papanicolaou Society of Cytopathology Task Force on Standards of Practice. Mod Pathol 1996; 9: 710-715

21 Cibas ES, Ali SZ. The Bethesda System For Reporting Thyroid Cytopathology. Am J Clin Pathol 2009; 132: 658-665 Hospital

22 Ivanac G, Brkljacic B, Ivanac $K$ et al. Vascularisation of benign and malignant thyroid nodules: CD US evaluation. Ultraschall in Med 2007; 28: $502-506$

23 Ophir J, Cespedes I, Ponnekanti $H$ et al. Elastography: a quantitative method for imaging the elasticity of biological tissues. Ultrason Imaging 1991; 13: $111-134$

24 Frey $H$. Realtime-elastography. A new ultrasound procedure for the reconstruction of tissue elasticity. Radiologe 2003; 43: 850-855

25 Asteria C, Giovanardi A, Pizzocaro A et al. US-elastography in the differential diagnosis of benign and malignant thyroid nodules. Thyroid 2008; $18: 523-531$

26 Rubaltelli L, Corradin S, Dorigo A et al. Differential diagnosis of benign and malignant thyroid nodules at elastosonography. Ultraschall in Med 2009; 30: 175-179

27 Friedrich-Rust M, Sperber A, Holzer K et al. Real-time Elastography and Contrast-Enhanced Ultrasound for the Assessment of Thyroid Nodules. Exp Clin Endocrinol Diabetes 2010; 118: 602-609

28 Robin X, Turck N, Hainard A et al. pROC: an open-source package for $\mathrm{R}$ and $\mathrm{S}+$ to analyze and compare ROC curves. BMC Bioinformatics 2011; $12: 77$

29 Ding J, Cheng H, Ning C et al. Quantitative measurement for thyroid cancer characterization based on elastography. J Ultrasound Med 2011; 30: $1259-1266$

30 Vorlander C, Wolff J, Saalabian S et al. Real-time ultrasound elastography-a noninvasive diagnostic procedure for evaluating dominant thyroid nodules. Langenbecks Arch Surg 2010; 395: 865 -871

31 Ning $C P$, Jiang SQ Zhang T et al. The value of strain ratio in differential diagnosis of thyroid solid nodules. Eur J Radiol 2012; 81: 286-291

32 Azizi G, Keller J, Lewis $M$ et al. Performance of elastography for the evaluation of thyroid nodules: a prospective study. Thyroid 2013; 23: $734-740$

33 Magri F, Chytiris S, Capelli V et al. Comparison of elastographic strain index and thyroid fine-needle aspiration cytology in 631 thyroid nodules. J Clin Endocrinol Metab 2013; 98: 4790-4797

34 Cantisani V, Lodise P, Di Rocco G et al. Diagnostic accuracy and interobserver agreement of Quasistatic Ultrasound Elastography in the diagnosis of thyroid nodules. Ultraschall in Med 2015; 36: 162 - 167

35 Lippolis PV, Tognini S, Materazzi G et al. Is elastography actually useful in the presurgical selection of thyroid nodules with indeterminate cytology? J Clin Endocrinol Metab 2011; 96: E1826-E1830

36 Unluturk U, Erdogan MF, Demir 0 et al. Ultrasound elastography is not superior to grayscale ultrasound in predicting malignancy in thyroid nodules. Thyroid 2012; 22: 1031-1038 
37 Rubaltelli L, Corradin S, Dorigo A et al. Differential Diagnosis of Benign and Malignant Thyroid Nodules at Elastosonography. Ultraschall in Med 2009; 30: 175-179

38 Hong Y, Liu X, Li Z et al. Real-time ultrasound elastography in the differential diagnosis of benign and malignant thyroid nodules. J Ultrasound Med 2009; 28: 861-867

39 Lyshchik A, Higashi T, Asato R et al. Thyroid gland tumor diagnosis at US Elastography. Radiology 2005; 237: 202-211

40 Rago T, Santini F, Scutari M et al. Elastography: new developments in ultrasound for predicting malignancy in thyroid nodules. J Clin Endocrinol Metab 2007; 92: 2917-2922

41 Bojunga J, Dauth N, Berner C et al. Acoustic radiation force impulse imaging for differentiation of thyroid nodules. PLoS One 2012; 7: e42735

42 Friedrich-Rust M, Meyer G, Dauth $N$ et al. Interobserver agreement of Thyroid Imaging Reporting and Data System (TIRADS) and strain elas- tography for the assessment of thyroid nodules. PLoS One 2013; 8: e77927

43 Trimboli P, Guglielmi R, Monti S et al. Ultrasound sensitivity for thyroid malignancy is increased by real-time elastography: a prospective multicenter study. J Clin Endocrinol Metab 2012; 97: 4524 - 4530

44 Cantisani V, Grazhdani H, Ricci P et al. Q-elastosonography of solid thyroid nodules: assessment of diagnostic efficacy and interobserver variability in a large patient cohort. Eur Radiol 2014; 24: 143-150

45 Lin P, Chen M, Liu B et al. Diagnostic performance of shear wave elastography in the identification of malignant thyroid nodules: a meta-analysis. Eur Radiol 2014; 24: 2729-2738

46 Lyshchik A, Higashi T, Asato R et al. Thyroid gland tumor diagnosis at US elastography. Radiology 2005; 237: 202 - 211 